\title{
XL.-a-Amino-a-plenylacetamide and Some of its Derivatives.
}

By Charles Hugh Clarke and Francis Francis.

Although Tiemann and Friedländer (Ber., 1881, 14, 1968) were unable to prepare $\boldsymbol{\alpha}$-amino- $\boldsymbol{\alpha}$-phenylacetamide in a pure state from its hydrochloride, we have found the base is stable, and may be easily obtained from mandelonitrile. The action of alcoholic ammonia on the aldehydecyanohydrins results in the formation of the a-amino-nitriles, but if the reaction is carried out in the presence of potassium hydroxide, partial saponification of the nitrile group takes place; and, if benzaldehydecyanohydrin is used, a-amino- $\alpha$-phenylacetamide is formed, thus:

$$
\mathrm{C}_{6} \mathrm{H}_{5} \cdot \mathrm{CH}(\mathrm{OH}) \cdot \mathrm{CN}+\mathrm{NH}_{3} \rightarrow \mathrm{C}_{6} \mathrm{H}_{5} \cdot \mathrm{CH}\left(\mathrm{NH}_{2}\right) \cdot \mathrm{CO} \cdot \mathrm{NH}_{2} \text {. }
$$

The isolation of the base from the other products of the reaction is difficult, but if the deccmposition is carried out in the presence of benzaldehyde, the well crystalline benzylidene derivative can be readily obtained to the extent of about 65 per cent. of the cyanohydrin taken, and $\alpha$-amino- $\alpha$-phenylacetamide is best prepared from it by treating it with phenylhydrazine, when the separation of the resulting benzaldehydephenylhydrazone from the base is easily carried out, and a quantitative yield obtained.

$\alpha$-Amino- $\alpha$-phenylacetamide is characterised by the readiness with which it condenses with aromatic aldehydes, forming products of the type $\mathrm{C}_{6} \mathrm{H}_{5} \cdot \mathrm{CH}(\mathrm{N}: \mathrm{CHR}) \cdot \mathrm{CO} \cdot \mathrm{NH}_{2}$. A similar reaction takes place with acetoacetic ester and ethylacetoacetic ester, but not with the diethyl derivative.

Greater interest lies in the ease with which the five-membered ring, phenylhydantoin, can be formed from the base. The carbethoxy-compound gives an 85 per cent. yield of phenylhydantoin when treated with alcoholic potassium hydroxide:

$$
\mathrm{C}_{6} \mathrm{H}_{5} \cdot \mathrm{CH}<\underset{\mathrm{CO} \cdot \mathrm{NH}_{2}}{\mathrm{NH} \cdot \mathrm{CO}_{2} \mathrm{Et}} \rightarrow \mathrm{EtOH}+\mathrm{C}_{6} \mathrm{H}_{5} \cdot \mathrm{CH}<\begin{gathered}
\mathrm{NH} \cdot \mathrm{CO} \\
\mathrm{CO}-\mathrm{NH}
\end{gathered} .
$$

The ease with which the base and its carbethoxy-derivative can be prepared renders this the best method for the preparation of this substance.

Corresponding experiments with a-amino-a-p-methoxyphenylacetamide showed that this also lent itself readily to the formation of p-methoxyphenylhyduntoin.

As compared with the ease with which five-membered rings of the above type can be formed is the difficulty experienced in the preparation of any six-membered heterocyclic derivative. 
Thus, it was not found possible to obtain a closed ring substance from the interaction of glyoxal and $\alpha$-amino- $\alpha$-phenylacetamide. Further, although chloroacetyl chloride gave a good yield of the corresponding chloroacetyl derivative,

$$
\mathrm{C}_{6} \mathrm{H}_{5} \cdot \mathrm{CH}\left(\mathrm{NH} \cdot \mathrm{CO} \cdot \mathrm{CH}_{2} \mathrm{Cl}\right) \cdot \mathrm{CO} \cdot \mathrm{NH}_{2} \text {, }
$$

it was again not found possible to eliminate hydrogen chloride, and form the six-membered closed chain.

Ethyl oxalate readily gives a condensation product,

$$
\mathrm{C}_{6} \mathrm{H}_{5} \cdot \mathrm{CH}\left(\mathrm{NH} \cdot \mathrm{CO} \cdot \mathrm{CO}_{2} \mathrm{Et}\right) \cdot \mathrm{CO} \cdot \mathrm{NH}_{2} \text {, }
$$

but this, on treatment with alcoholic potassium hydroxide or sodium ethoxide, gives the alkali salt of the corresponding acid, $\mathrm{C}_{6} \mathrm{H}_{5} \cdot \mathrm{CH}\left(\mathrm{NH} \cdot \mathrm{CO} \cdot \mathrm{CO}_{2} \mathrm{H}\right) \cdot \mathrm{CO} \cdot \mathrm{NH}_{2}$, and from this substance and its previously-mentioned ethyl ester we were unable to form any cyclic derivative.

$$
\begin{gathered}
\text { EXPERIMENTAL. } \\
a-B e n z y l i d e n e a m i n o-\alpha-p h e n y l a c e t a m i d e, \\
\mathrm{C}_{6} \mathrm{H}_{5} \cdot \mathrm{CH}\left(\mathrm{N}: \mathrm{CH} \cdot \mathrm{C}_{6} \mathrm{H}_{5}\right) \cdot \mathrm{CO} \cdot \mathrm{NH}_{2} \cdot
\end{gathered}
$$

Ten grams of benzaldehydecyanohydrin and 7 grams of benzaldehyde are dissolved in a small quantity of alcohol, and treated with a mixture of 10 c.c. of a 15 per cent. solution of potassium hydroxide with 10 c.c. of aqueous ammonia (D 0.880).

Sufficient alcohol is then added to give a clear solution. Reaction commences at once, and it is necessary to add small quantities of alcohol from time to time to keep the liquid clear.

After twelve hours, the crystalline condensation product which has separated is collected, washed with ether, and recrystallised from benzene. From this solvent 10 to 12 grams separate on cooling, consisting of colourless plates, melting at $120-121^{\circ}$, insoluble in water, but soluble in hot benzene or alcohol:

0.1842 gave $0.0991 \mathrm{H}_{2} \mathrm{O}$ and $0.5126 \mathrm{CO}_{2} . \mathrm{C}=75.9 ; \mathrm{H}=5.98$.

$0 \cdot 1760$ " $17 \cdot 7$ c.c. $\mathrm{N}_{2}$ at $17^{\circ}$ and $752 \mathrm{~mm}$. $\mathrm{N}=11 \cdot 6$.

$\mathrm{C}_{15} \mathrm{H}_{14} \mathrm{ON}_{2}$ requires $\mathrm{C}=75.6 ; \mathrm{H}=5.90 ; \mathrm{N}=11.8$ per cent.

$$
\alpha \text {-Amino- } \alpha \text {-phenylacetamide, } \mathrm{C}_{6} \mathrm{H}_{5} \cdot \mathrm{CH}\left(\mathrm{NH}_{2}\right) \cdot \mathrm{CO} \cdot \mathrm{NH}_{2} \text {. }
$$

The hydrochloride of this base, previously described by Tiemann and Friedländer, is readily obtained by the action of hydrochloric acid on the benzylidene derivative just described.

As this salt is readily soluble only in hot water, a hot solution must be treated with aqueous potassium hydroxide in order to obtain the base. This treatment results in a partial saponification, and the method consequently gives only a very small quantity of $\alpha$-amino- $\alpha$-phenylacetamide. In this probably lies the explanation for the supposed instability of this base. 
On the other hand, the tartrate is readily soluble in water, and can be obtained by the decomposition of the benzylidene derivative with a solution of tartaric acid. On removal of the resulting benzaldehyde with ether, the base can be precipitated from a concentrated solution in the cold by means of potassium hydroxide. It may be mentioned here that the tartrate does not lend itself to the separation of the base into its optical components.

The best method for the isolation of the substance in question consists in warming the benzylidene derivative with the calculated amount of phenylhydrazine in benzene solution. The resulting $\alpha$-amino- $\alpha$-phenylacetamide is only sparingly soluble in this medium, and separates first. On cooling, the benzaldehydephenylhydrazone crystallises out, and from this a further amount of base may be extracted by warm water. By this method, a yield of 90 per cent. of the base may be obtained.

$\alpha$-Amino- $\alpha$-phenylacetamide is readily soluble in water or alcohol, sparingly so in ether, and almost insoluble in benzene. It is best recrystallised from a mixture of benzene and alcohol, from which it separates on cooling in colourless plates, melting at $130^{\circ}$. Its aqueous solution gives a strongly alkaline reaction, and may be evaporated to dryness without decomposition taking place:

(1) 0.2024 gave $0.4809 \mathrm{CO}_{2}$ and $0.1220 \mathrm{H}_{2} \mathrm{O} . \mathrm{C}=64 \cdot 8 ; \mathrm{H}=6 \cdot 7$.

$0.1920,31 \cdot 0$ c.c. $\mathrm{N}_{2}$ at $16^{\circ}$ and $758 \mathrm{~mm}$. $\mathrm{N}=18 \cdot 8$.

(2) $0.1620,0.3819 \mathrm{CO}_{2}$ and $0.0977 \mathrm{H}_{2} \mathrm{O} . \quad \mathrm{C}=64 \cdot 3 ; \mathrm{H}=6.7$.

$0 \cdot 1524,24 \cdot 8$ c.c. $\mathrm{N}_{2}$ at $18^{\circ}$ and $750 \mathrm{~mm}$. $\mathrm{N}=18^{\circ} 6$.

$\mathrm{C}_{8} \mathrm{H}_{10} \mathrm{ON}_{2}$ requires $\mathrm{C}=64.0 ; \mathrm{H}=6.7 ; \mathrm{N}=18.6$ per cent.

$\boldsymbol{\alpha}$-Amino- $\alpha$-phenylacetamide readily gives condensation products with aromatic aldehydes similar to the benzaldehyde derivative previously mentioned. These may be prepared in quantitative yield by warming together molecular quantities of the aldehyde with the base in alcoholic solution.

The salicylidene derivative, $\mathrm{C}_{6} \mathrm{H}_{5} \cdot \mathrm{CH}\left(\mathrm{N}: \mathrm{CH} \cdot \mathrm{C}_{6} \mathrm{H}_{4} \cdot \mathrm{OH}\right) \cdot \mathrm{CO} \cdot \mathrm{NH}_{2}$, when recrystallised from hot alcohol, melts at $150^{\circ}$ :

0.2116 gave $0.5506 \mathrm{CO}_{2}$ and $0.1140 \mathrm{H}_{2} \mathrm{O} . \quad \mathrm{C}=70.9 ; \mathrm{H}=5.98$. $\mathrm{C}_{15} \mathrm{H}_{14} \mathrm{O}_{2} \mathrm{~N}_{2}$ requires $\mathrm{C}=70.9 ; \mathrm{H}=5.51$ per cent.

The o-methoxybenzylidene derivative,

$$
\mathrm{C}_{6} \mathrm{H}_{5} \cdot \mathrm{CH}\left(\mathrm{N}: \mathrm{CH} \cdot \mathrm{C}_{6} \mathrm{H}_{4} \cdot \mathrm{OMe}\right) \cdot \mathrm{CO} \cdot \mathrm{NH}_{2} \text {, }
$$

is not formed so easily as the preceding. When recrystallised from alcohol, it melts at $174-175^{\circ}$ :

0.2180 gave 20.4 c.c. $\mathrm{N}_{2}$ at $12^{\circ}$ and $750.5 \mathrm{~mm}$. $\mathrm{N}=10.9$. $\mathrm{C}_{16} \mathrm{H}_{16} \mathrm{O}_{2} \mathrm{~N}_{2}$ requires $\mathrm{N}=10.5$ per cent.

The p-methoxybenzylidene derivative was prepared by heating the alcoholic solution of anisaldehyde and base for some hours

VOL. XCIX. 
before the condensation was complete. It crystallises from hot alcohol in colourless needles, melting at $164-165^{\circ}$ :

0.1894 gave $17 \cdot 8$ c.c. $\mathrm{N}_{2}$ at $17^{\circ}$ and $762 \mathrm{~mm}$. $\mathrm{N}=10.9$.

$\mathrm{C}_{16} \mathrm{H}_{16} \mathrm{O}_{2} \mathrm{~N}_{2}$ requires $\mathrm{N}=10.5$ per cent.

\section{Ethyl $\beta$-Carbamylphenylmethylaminocrotonate, $\mathrm{NH}_{2} \cdot \mathrm{CO} \cdot \mathrm{CHPh} \cdot \mathrm{NH} \cdot \mathrm{CMe}: \mathrm{CH} \cdot \mathrm{CO}_{2} \mathrm{Et}$.}

When molecular quantities of acetoacetic ester and the base are heated together in alcoholic solution with a trace of sodium ethoxide, a quantitative yield of the condensation product separates out on the addition of water. It is only sparingly soluble in benzene or ether, and best recrystallised from dilute alcohol, from which it separates in colourless needles, melting at $150^{\circ}$ :

0.2814 gave 27.2 c.c. $\mathrm{N}_{2}$ at $14^{\circ}$ and $738 \mathrm{~mm}$. $\mathrm{N}=11^{\circ} 0$.

$$
\mathrm{C}_{14} \mathrm{H}_{18} \mathrm{O}_{3} \mathrm{~N}_{2} \text { requires } \mathrm{N}=10.7 \text { per cent. }
$$

Ethylacetoacetic ester gave a corresponding derivative, melting at $132^{\circ}$, which was not analysed, but no condensation product could be obtained from diethylacetoacetic ester.

\section{Preparation of Phenylhydantoin.}

Both the carbomethoxy- and carbethoxy-derivatives of aminophenylacetamide were prepared and investigated in order to find which condensed more readily to the hydantoin.

a-Carbomethoxyamino-a-phenylacetamide,

$$
\mathrm{C}_{6} \mathrm{H}_{5} \cdot \mathrm{CH}\left(\mathrm{NH} \cdot \mathrm{CO}_{2} \mathrm{Me}\right) \cdot \mathrm{CO} \cdot \mathrm{NH}_{2} \text {, }
$$

is readily obtained in quantitative yield by shaking a solution of the base in water containing sodium carbonate with methyl chloroformate. It crystallises from dilute alcohol in colourless plates, melting at $210^{\circ}$, and is readily soluble in hot water or alcohol:

0.1356 gave 16.6 c.c. $\mathrm{N}_{2}$ at $18^{\circ}$ and $751 \mathrm{~mm}$. $\mathrm{N}=13.9$.

$$
\mathrm{C}_{10} \mathrm{H}_{12} \mathrm{O}_{3} \mathrm{~N}_{2} \text { requires } \mathrm{N}=13.4 \text { per cent. }
$$

a-Carbethoxyamino-a-phenylacetamide,

$$
\mathrm{C}_{6} \mathrm{H}_{5} \cdot \mathrm{CH}\left(\mathrm{NH} \cdot \mathrm{CO}_{2} \mathrm{Et}\right) \cdot \mathrm{CO} \cdot \mathrm{NH}_{2} \text {, }
$$

may be prepared in a similar manner to the previous derivative by employing ethyl chloroformate. It is only sparingly soluble in the ordinary organic solvents, and is best recrystallised from dilute pyridine, from which it separates in small, brilliant needles, melting at $202^{\circ}$ :

0.2664 gave 30.4 c.c. $\mathrm{N}_{2}$ at $22^{\circ}$ and $760 \mathrm{~mm}$. $\mathrm{N}=12.9$. $\mathrm{C}_{11} \mathrm{H}_{14} \mathrm{O}_{3} \mathrm{~N}_{2}$ requires $\mathrm{N}=12 \cdot 6$ per cent.

When this derivative is warmed with dilute hydrochloric acid, it dissolves, and, on cooling, $\alpha$-carbethoxyamino-a-phenylacetic acid, melting at $118^{\circ}$, crystallises out: 


\subsection{8 gave 8.4 c.c. $\mathrm{N}_{2}$ at $19^{\circ}$ and $749.5 \mathrm{~mm} . \quad \mathrm{N}=6.7$. $\mathrm{C}_{11} \mathrm{H}_{13} \mathrm{O}_{4} \mathrm{~N}$ requires $\mathrm{N}=6.3$ per cent.}

No difference was found in the ease with which the carbomethoxyor carbethoxy-derivative split off methyl and ethyl alcohols respectively to form phenylhydantoin.

When, for instance, $a$-carbethoxyamino- $\alpha$-phenylacetamide was warmed with dilute alcoholic potassium hydroxide, it slowly dissolved, and on diluting with water and acidifying with hydrochloric acid, an 85 per cent. yield of phenylhydantoin (m. p. $178^{\circ}$ ) was obtained. (Found, $\mathrm{N}=15 \cdot 5$. Calc., $\mathrm{N}=15 \cdot 8$ per cent.)

\section{a-p-Methoxybenzylideneamino-a-p-methoxyphenylacetamide, $\mathrm{MeO} \cdot \mathrm{C}_{6} \mathrm{H}_{4} \cdot \mathrm{CH}\left(\mathrm{N}: \mathrm{CH} \cdot \mathrm{C}_{6} \mathrm{H}_{4} \cdot \mathrm{OMe}\right) \cdot \mathrm{CO} \cdot \mathrm{NH}_{2}$.}

A 60 per cent. yield of this substance can be obtained by treating a mixture of anisaldehyde and anisaldehydecyanohydrin with a solution of potassium hydroxide and ammonia, as previously described. The derivative, which separates after some time, recrystallises from alcohol and benzene, and melts at $141^{\circ}$ :

0.1600 gave $0.4024 \mathrm{CO}_{2}$ and $0.0926 \mathrm{H}_{2} \mathrm{O} . \mathrm{C}=68.6 ; \mathrm{H}=6.44$.

$0 \cdot 1884,16.0$ c.c. $\mathrm{N}_{2}$ at $23^{\circ}$ and $751 \mathrm{~mm}$. $\mathrm{N}=9 \cdot 45$.

$\mathrm{C}_{17} \mathrm{H}_{18} \mathrm{O}_{3} \mathrm{~N}_{2}$ requires $\mathrm{C}=68.4 ; \mathrm{H}=6.04 ; \mathrm{N}=9.39$ per cent.

An 80 per cent. yield of the free base itself, a-amino-a-p-methoxyphenylacetamide, $\mathrm{MeO} \cdot \mathrm{C}_{6} \mathrm{H}_{4} \cdot \mathrm{CH}\left(\mathrm{NH}_{2}\right) \cdot \mathrm{CO} \cdot \mathrm{NH}_{2}$, can be obtained from this condensation product by the use of phenylhydrazine in a similar manner to that previously described in the case of the phenyl derivative.

The base is soluble in water, sparingly so in benzene, and may be recrystallised from a mixture of benzene and alcohol, from which medium it is obtained in colourless needles, melting at $134^{\circ}$ :

$0 \cdot 1060$ gave $14 \cdot 8$ c.c. $\mathrm{N}_{2}$ at $19^{\circ}$ and $748.5 \mathrm{~mm}$. $\mathrm{N}=15 \cdot 8$. $\mathrm{C}_{9} \mathrm{H}_{12} \mathrm{O}_{2} \mathrm{~N}_{2}$ requires $\mathrm{N}=15 \cdot 6$ per cent.

The benzoyl derivative crystallises from alcohol, and melts at $184^{\circ}$ :

0.1440 gave 13.2 c.c. $\mathrm{N}_{2}$ at $23^{\circ}$ and $763 \mathrm{~mm}$. $\mathrm{N}=10 \cdot 4$. $\mathrm{C}_{16} \mathrm{H}_{16} \mathrm{O}_{3} \mathrm{~N}_{2}$ requires $\mathrm{N}=9 \cdot 9$ per cent.

The carbethoxy-derivative crystallises from hot water, and melts at $223^{\circ}$ :

0.1560 gave 15.6 c.c. $\mathrm{N}_{2}$ at $20^{\circ}$ and $757.5 \mathrm{~mm} . \mathrm{N}=11.4$. $\mathrm{C}_{12} \mathrm{H}_{16} \mathrm{O}_{4} \mathrm{~N}_{2}$ requires $\mathrm{N}=11.2$ per cent.

When this substance is treated with alcoholic potassium hydroxide, the solution diluted and acidified in a similar manner to that previously described, an 80 per cent. yield of p-methoxy- 
phenylhydantoin is obtained. When crystallised from hot water, it melts at $188-189^{\circ}$ :

0.1344 gave 16.4 c.c. $\mathrm{N}_{2}$ at $22 \cdot 5^{\circ}$ and $749 \mathrm{~mm}$. $\mathrm{N}=13 \cdot 6$.

$$
\mathrm{C}_{10} \mathrm{H}_{10} \mathrm{O}_{3} \mathrm{~N}_{2} \text { requires } \mathrm{N}=13 \cdot 6 \text { per cent. }
$$

The following derivatives were investigated in order to see whether it was possible to prepare six-membered rings from them. In all cases negative results were obtained.

$\alpha$-Chloroacetylamino-a-phenylacetamide,

$$
\mathrm{C}_{6} \mathrm{H}_{5} \cdot \mathrm{CH}\left(\mathrm{NH} \cdot \mathrm{CO} \cdot \mathrm{CH}_{2} \mathrm{Cl}\right) \cdot \mathrm{CO} \cdot \mathrm{NH}_{2} \text {, }
$$

was obtained by the action of chloroacetyl chloride on aminophenylacetamide in benzene solution, in the presence of anhydrous sodium carbonate. The reaction takes place slowly at the temperature of the boiling solvent.

The derivative, which melts at $170^{\circ}$, is only sparingly soluble in benzene or ether, and may be crystallised from hot water and alcohol :

$$
\begin{aligned}
& 0.2340 \text { gave } 26 \cdot 4 \text { c.c. } \mathrm{N}_{2} \text { at } 18^{\circ} \text { and } 741 \mathrm{~mm} . \quad \mathrm{N}=12 \cdot 7 . \\
& \qquad \mathrm{C}_{10} \mathrm{H}_{11} \mathrm{O}_{2} \mathrm{~N}_{2} \mathrm{Cl} \text { requires } \mathrm{N}=12 \cdot 4 \text { per cent. }
\end{aligned}
$$

\section{Reaction with Diethyl Oxalate.}

When the base is warmed for a short time with diethyl oxalate, a solid separates, which, when crystallised from a mixture of alcohol, water, and ethyl acetate, melts and decomposes at $195^{\circ}$.

The analysis given below, and the properties, showed that this was the ethyl hydrogen oxalate of the base,

$$
\mathrm{C}_{6} \mathrm{H}_{5} \cdot \mathrm{CH}\left(\mathrm{NH}_{2}\right) \cdot \mathrm{CO} \cdot \mathrm{NH}_{2}, \mathrm{CO}_{2} \mathrm{H} \cdot \mathrm{CO}_{2} \mathrm{Et} \text {, }
$$

probably formed by the presence of a small quantity of water. It was not further investigated:

0.1456 gave $0.2854 \mathrm{CO}_{2}$ and $0.0870 \mathrm{H}_{2} \mathrm{O} . \quad \mathrm{C}=53.5 ; \mathrm{H}=6.6$.

$$
\mathrm{C}_{12} \mathrm{H}_{16} \mathrm{O}_{5} \mathrm{~N}_{2} \text { requires } \mathrm{C}=53.7 ; \mathrm{H}=6.0 \text { per cent. }
$$

When the base and diethyl oxalate are heated together for some time, the salt just described, which separates at first, soon dissolves. If this solution is then boiled for one hour, on cooling, a quantitative yield of a-ethyloxalylamino-a-phenylacetamide,

is obtained.

$$
\mathrm{C}_{6} \mathrm{H}_{5} \cdot \mathrm{CH}\left(\mathrm{NH} \cdot \mathrm{CO} \cdot \mathrm{CO}_{2} \mathrm{Et}\right) \cdot \mathrm{CO} \cdot \mathrm{NH}_{2} \text {, }
$$

It crystallises from benzene in colourless needles, melting at $116^{\circ}$ :

0.1792 gave $17 \cdot 4$ c.c. $\mathrm{N}_{2}$ at $17 \cdot 5^{\circ}$ and $765 \mathrm{~mm}$. $\mathrm{N}=11 \cdot 3$.

$$
\mathrm{C}_{12} \mathrm{H}_{14} \mathrm{O}_{4} \mathrm{~N}_{2} \text { requires } \mathrm{N}=11.2 \text { per cent. }
$$

When an alcoholic solution of this condensation product is treated with alcoholic potassium hydroxide, the potassium salt of a-oxalylamino-a-phenylacetamide,

$$
\mathrm{C}_{6} \mathrm{H}_{6} \cdot \mathrm{CH}\left(\mathrm{NH} \cdot \mathrm{CO} \cdot \mathrm{CO}_{2} \mathrm{H}\right) \cdot \mathrm{CO} \cdot \mathrm{NH}_{2} \text {, }
$$


BOYLE: IODOBENZENEMONOSULPHONIC ACIDS. PART III. 325

separates out, and when this is decomposed by acids the free acid itself is obtained.

It is soluble in water or alcohol, and crystallises from ethyl acetate in colourless needles, melting and decomposing at $180^{\circ}$ :

0.1782 gave 19.4 c.c. $\mathrm{N}_{2}$ at $16^{\circ}$ and $768 \mathrm{~mm} . \quad \mathrm{N}=12.8$.

$$
\mathrm{C}_{10} \mathrm{H}_{10} \mathrm{O}_{4} \mathrm{~N}_{2} \text { requires } \mathrm{N}=12 \cdot 6 \text { per cent. }
$$

We were unable to form any six-membered cyclic derivatives from this substance or its ethyl ester; various methods usually employed for the purpose, and those which gave almost quantitative yields of hydantoins, yielded negative results in all cases.

Chemical Defartment,

UNIVERSITY OF BRISTOL. 